\title{
Simulation and optimization of micro power generation process by utilizing urban natural gas pipeline pressure energy
}

\author{
Xiaxi Li \& Hui Zhang ${ }^{1 \star}$, Wendong $\mathrm{Xu}^{2}$, Linlin Xing\& Wei Duan ${ }^{2}$ \\ 1Beijing gas group co., LTD, Beijing, China \\ 2South China University of Technology, Guangzhou, Guangdong, China
}

Keywords: Gas pipeline; Pressure energy; Natural gas; Power generation; Simulation and optimization.

\begin{abstract}
Transmission pipelines carrying natural gas across long distances often work at high pressures (up to $10 \mathrm{MPa}$ ). The high-pressure natural gas is regulated though a throttling device, which results in much waste of pressure energy. Meanwhile, more pressure reducing stations exist the problem of no electric or lack of electric. In this paper, a novel micro power generating process is designed and simulated by Aspen Plus software to utilize the pressure energy. Voltage is selected as the objective function of the process optimization, with several variables. The available energy of whole process is also calculated and discussed. Furthermore, the exergy losses and efficiency are evaluated and analyzed in details. The results showed when the process properly runs, electricity facilities voltage is $220 \mathrm{~V}$, the best expansion ratio range is $3.0 \sim 3.0$, the optimal speed range is $650 \sim 750 \mathrm{r} / \mathrm{min}$, the optimal noise range is $71 \sim 72 \mathrm{~dB}$, the corresponding power is $2.6 \sim 2.8 \mathrm{~kW}$. The process capacity is not much, $2 \sim 3 \mathrm{~kW}$ output can satisfy the demand of most of the city, to solve the gas pressure regulating stations widespread without electricity, less electricity, and other issues. This process has forward popularization value.
\end{abstract}

\section{INTRODUCTION}

Natural gas is a kind of high-efficient, clean energy and has the characteristics of abundant storage and stable price[Zhang Hui, 2013]. At present, natural gas is generally transported with highpressure pipeline to each big gas pressure reduction station. And high-pressure natural gas is generally adjusted to mid-pressure or low-pressure step by step by pressure regulator, then goes to the downstream users. In the traditional pressure regulating process, not only is a tremendous amount of potential pressure energy wasted, but it also poses a threat to the pipeline and equipment because of a sharp cooling. Under the circumstances of tight energy, it is great vital that the part of pressure energy is effectively recycled [Xu Wendong,2010][Mehmet Alparslan Neseli,2015][Mahmood Farzaneh Gord,2014].

The main methods of pressure energy utilization are generating and refrigeration. And more generating technology using pressure energy has been studied. In Tokyo electric power company, it was adopted that high-pressure natural gas directly expands to generate and a capacity of $7700 \mathrm{~kW}$ generation demonstration station was constructed [Anonymity. 2009]. And generating using pressure energy has realized industrialization. Wen-dong $\mathrm{Xu}$, professor of South China University of Technology, has done some scientific and technical research in urban natural gas pipeline pressure energy generating technology [Chen Qiuxiong, 2012]. And he developed the first generating-ice demonstration station using natural gas pressure energy, which generated $200 \mathrm{~kW}$ with a total investment of about 10 million RMB and annual revenue of 1.46 million RMB [An Chengming,2012].

Recycling huge pressure is currently the new energy-saving technology in the natural gas industry and has the advantages of eliminating equipment security risks and economy [Li Xiaxi, 2014]. If the technology was used in natural gas pipeline, not only would it solve shortage power in remote pressure drop stations, it would also replace or reduce municipal electricity in the workplace, opening up new avenues of energy-saving for the enterprises. 


\section{PROCESS DESIGN}

\section{Gas parameters}

The pressure of the pipeline gas is set at $0.8 \mathrm{MPa}$, the temperature is at $15{ }^{\circ} \mathrm{C}$ and the flow rate is assumed at $150 \mathrm{Nm} 3 / \mathrm{h}$. This generating process is a kind of direct NG expansion to drive expander to generate. Most part of the feed natural gas is expanded to $0.1 \mathrm{MPa}$ and then enters the low-pressure network. The mole fraction of each component for the natural gas and other parameters in the process are given in Table 1.

Table 1. Mole fraction of components for natural gas and other parameters in the process

\begin{tabular}{llc}
\hline Parameter & Parameter Value \\
\hline Feed gas temperature & $20{ }^{\circ} \mathrm{C}$ & \\
Feed gas pressure & $0.8 \mathrm{MPa}$ & \\
Feed gas flow rate & $150 \mathrm{Nm}^{3} / \mathrm{h}$ & \\
& $\mathrm{CH}_{4}$ & 0.8939 \\
& $\mathrm{C}_{2} \mathrm{H}_{6}$ & 0.0576 \\
& $\mathrm{C} 3 H 8$ & 0.033 \\
& $\mathrm{i}-\mathrm{C}_{4} \mathrm{H}_{10}$ & 0.0078 \\
Feed as mole fraction & $\mathrm{n}^{-\mathrm{C}_{4} \mathrm{H}_{10}}$ & \\
\multicolumn{1}{c}{ components } & 0.0066 & \\
& $\mathrm{CO}_{2}$ & 0 \\
& $\mathrm{~N}_{2}$ & 0.0011 \\
& Total & 1 \\
Entropy efficiency of expander & 0.8 & \\
Mechanical efficiency of expander & 0.78 & \\
\hline
\end{tabular}

\section{Generation using pressure process}

Many natural gas gate stations exist the common problem of no power or lack of electricity, with the characteristics of low power consumption. Micro power generation process is designed in this paper, and the capacity for this process is $5 \mathrm{~kW}$.

Taking certain high pressure A gate station as an example, the pressure ranges from $0.8 \mathrm{MPa}$ to $0.095 \mathrm{MPa}$. As is shown in figure.1, the process bypasses the original pressure regulating process. After it is filtered, gas goes to current limiter 3, passes to flowmeter 4, and then enters the motor 7 to drive generator 8 . The temperature of natural gas from motor rises and pressure turns into stability in the temperature and pressure balancer 9, then natural gas goes through pressure regulator 11, turning into low-pressure and entering the pipeline.

Electricity is delivered to control office 12 by buried cable, then passes to three-phase voltage regulator 13. A part of electricity is output in the form of $220 \mathrm{~V} \mathrm{AC}$, and another is stored in the battery 14, then passes to inverter 15 turning into 24V AC supply for the electric testing equipment 16.

Through automatic and remote control import and export solenoid valves, the whole system achieves seamless switch. Solenoid valve has four control points: inlet pressure, outlet pressure, outlet temperature and motor rotate speed. Inlet pressure control point is $1 \mathrm{MPa}$, outlet pressure control point is $0.13 \mathrm{MPa}$, outlet temperature control point is $-10{ }^{\circ} \mathrm{C}$ and rotate speed control point is $1000 \mathrm{r} / \mathrm{min}$. According to the load and flow demand for rotate speed, pneumatic control valve 2 can self-adjust, to realize automatic control. 


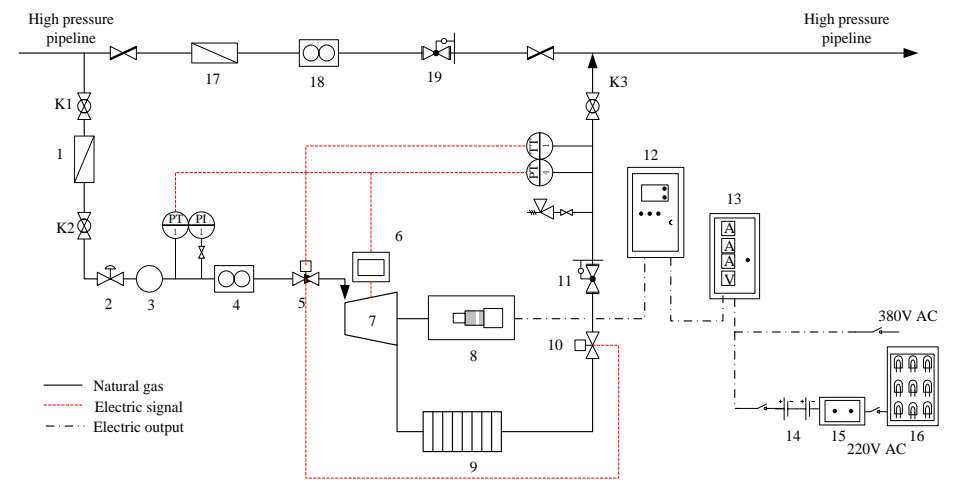

1,17-Filter； 2- Pneumatic valve; 3- Current limiter; 4,18-Flowmeter； 5- Solenoid valve D1； 6- Rotational speed test instrumen; 7-Monitor; 8-Generator; 9-Temperature and pressure balancer; 10- Solenoid valve D2; 11,19- Pressure regulator; 12- Control office; 13- Three-phase voltage regulator; 14-24V battery; 15- Inverter; 16- Electric testing equipment

Figure. 1 The process of micro power generation by utilizing natural gas pipeline pressure energy.

Phase equilibrium equations

Phase equilibrium equation is the basis for calculating physical parameters in the generating process. Redilich Kwong Soave (SRK) equation is used in this paper. The SRK equation is given as below:

$$
p=\frac{R T}{V-b}-\frac{a}{V(V+b)}
$$

where

$$
\begin{gathered}
a=a_{c} \cdot \alpha\left(T_{r}, \omega\right) \\
b \approx 0.08664 \frac{R T_{c}}{p_{c}}
\end{gathered}
$$

$$
\alpha^{0.5}=1+\left(0.48+1.57 \omega-0.176 \omega^{2}\right)\left(1-T_{r}^{0.5}\right)
$$

\section{Process optimization}

\section{Optimization of key parameters}

Voltage is a major fact for the evaluation of different generating process, therefore it is usually regarded as the objective function of the process optimization. Several parameters have a great impact on the voltage, including expansion ratio $(\zeta)$, rotate speed(r), and noise(v).

The voltage is affected by this three parameters $\zeta, \mathrm{r}, \mathrm{v}$. The voltage can be shown as below:

Voltage $=\mathrm{f}(\zeta, \mathrm{r}, \mathrm{v})$

\section{The effect of the expansion ratio of the expander on the process performance}

Expansion ratio has a great effect on the power and voltage. The effects of expansion ratio of the expander on the process performance are shown in Figure. 2. With the increase of expansion ratio, the power and the voltage relatively significantly increase. The greater the expansion ratio, the utilization potential of pipeline pressure energy is greater. Consequently, power and voltage both add up with the increase of expansion ratio.

From figure. 2, it can be also gotten that when the voltage is $220 \mathrm{~V}$ (point a), the expansion ratio of point $\mathrm{b}$ is $3.0 \sim 3.3$ and the power of point $d$ is $2.6 \sim 2.8 \mathrm{~kW}$. 


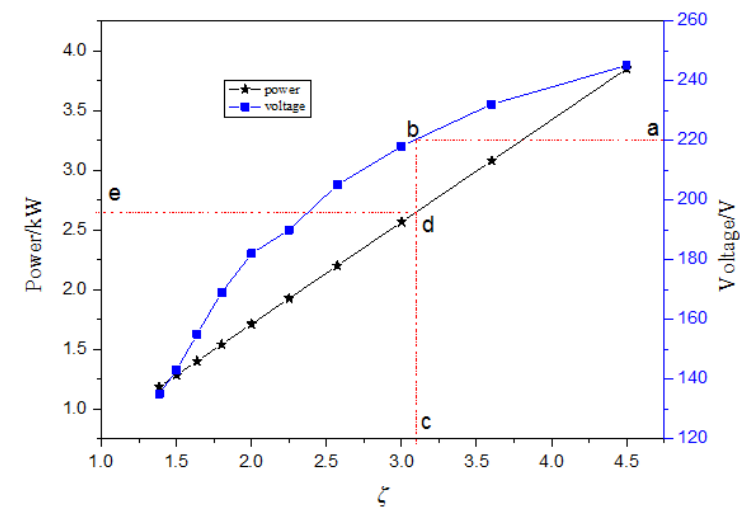

Figure.2. The curves of the power and voltage versus expansion ratio

The effect of the rotate speed of the expander on the process performance

The rotate speed of the expander has a significant influence on the process performance. Figure 3 shows the variations of power and voltage as the function of the rotate speed of the expander. With the increase of the rotate speed, the power and the voltage relatively significantly increase. This is because when rotate speed increases, more natural gas enters the expander to drive the generator, meanwhile the voltage adds up. And voltage and rotate speed has the relationship: $U=3.3+0.32 \mathrm{r}$, ( $\mathrm{U}$ and $r$ respectively stand for voltage and rotate speed).

From Figure. 3, it can be also gotten that when the voltage is $220 \mathrm{~V}$ (point a), the rotate speed of point $\mathrm{b}$ is $650 \sim 750 \mathrm{r} / \mathrm{min}$ and the power of point $\mathrm{d}$ is $2.6 \sim 2.8 \mathrm{~kW}$.

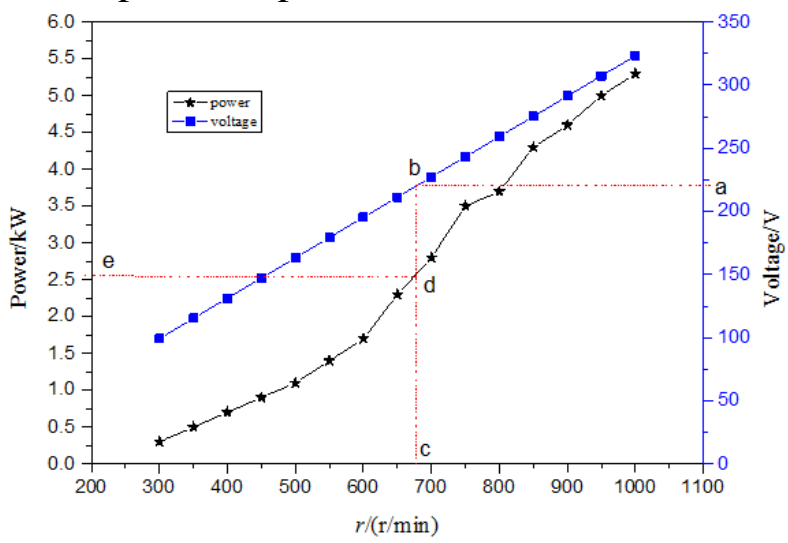

Figure.3. The curves of the power and voltage versus rotate speed

\section{The effect of the noise on the process performance}

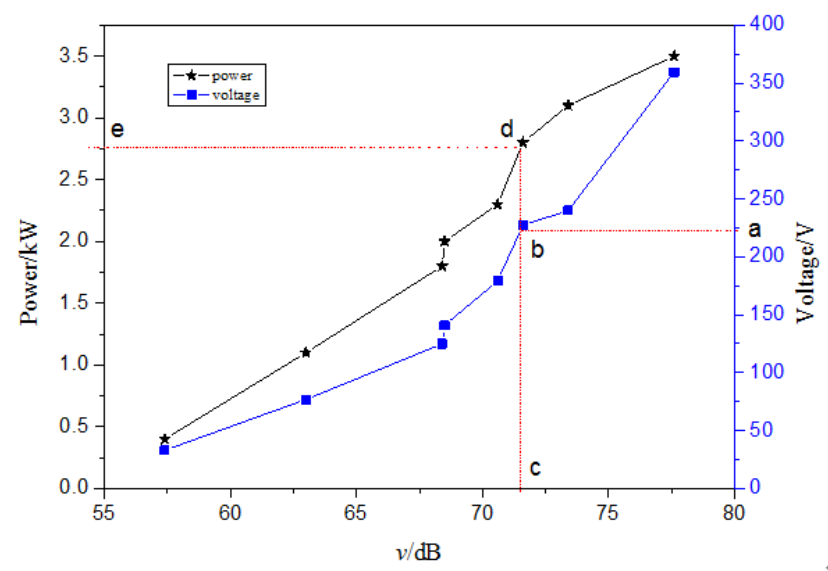

Figure 4. The curves of the power and voltage versus voice

With the rapid development of industry, noise is increasingly become the focus of one of the sources of pollution, consequently noise is also one of important factors restricting the development of the process. According to the national standard, it is qualified for not more than $85 \mathrm{~dB}$ noise at 1.5 meters distance. Figure 4 shows the variations of power and voltage as the function of the noise. With the increase of the noise, the power and the voltage relatively significantly increase. This is 
because that when more power is produced, the frequency of the expander is faster, and more noise occurs.

From Figure 4, it can be also gotten that when the voltage is $220 \mathrm{~V}$ (point a), the noise of point $\mathrm{b}$ is about $71 \sim 72 \mathrm{~dB}$ and the power of point $\mathrm{d}$ is about $2.6 \sim 2.8 \mathrm{~kW}$.

The main parameters of the micro power generation process are optimized by utilizing the gas pipeline pressure energy, as shown in Table 2.

Table 2. The main parameters of the process performance

\begin{tabular}{|l|l|l|l|l|}
\hline voltage & $\begin{array}{l}\text { expansion } \\
\text { ratio }\end{array}$ & rotate speed & noise & power \\
\hline $220 \mathrm{~V}$ & $3.0 \sim 3.3$ & $650 \sim 750 \mathrm{r} / \mathrm{min}$ & $71 \sim 72 \mathrm{~dB}$ & $2.6 \sim 2.8 \mathrm{~kW}$ \\
\hline
\end{tabular}

\section{Exergy analysis}

\section{The available pressure energy of the gas pipeline}

The natural gas pipeline network can be regarded as a steady opening system. Exergy analysis is used to calculate the available pressure energy of the gas pipeline. The unit mass exergy of a steady opening system can be formulated as follow:

$$
e_{x, h}=h-h_{0}-T_{0}\left(s-s_{0}\right)
$$

According to thermodynamical entroy relationship, the unit mass exergy of an opening system can be rewritten as:

$$
\begin{aligned}
& e_{x, h}=h-h_{0}-T_{0}\left(c_{p} \ln \frac{T}{T_{0}}-\frac{R}{M} \ln \frac{p}{p_{0}}\right) \\
& e_{x, h}=\left(h-h_{0}-T_{0} c_{p} \ln \frac{T}{T_{0}}\right)-\frac{R}{M} \ln \frac{p}{p_{0}}
\end{aligned}
$$

$$
e_{x, h}=e_{x, T}+e_{x, p}
$$

From the formulation, one can be seen as the pressure rises, the unit exergy is also increased. Therefore, it is very necessary to recovery the pressure energy of natural gas pipelines.

\section{Exergy analysis}

The system mainly includes expander, and exergy analysis is applied to the system to evaluate its exergy efficiency and exergy loss. Zhang introduced the equation of exergy loss [Zhang Hui, 2014]. The equation is shown as following:

$$
\begin{aligned}
\eta_{\exp } & =\frac{E_{x, \text { eff }}}{E_{x, \text { sup }}}=\frac{W_{E X P}}{m\left(e_{x, 1}-e_{x, 2}\right)} \\
E_{x, \text { loss }} & =E_{x, \text { sup }}-E_{x, \text { eff }}=m\left(e_{x, 1}-e_{x, 2}\right)-W_{E X P}
\end{aligned}
$$

Where $\eta_{\exp }$ indicates the exergy efficiency, $E_{x, \text { eff }}$ the efficient exergy, $E_{x, \text { sup }}$ the supply exergy, $W_{E X P}$ the expander exergy, $e_{x, 1}$ the specific exergy of input logistics, ${ }_{x, 2}$ the specific exergy of output logistics, $E_{x, \text { loss }}$ the loss exergy.

The result of exergy analysis is shown in Table 2. It can be found that $22.69 \%$ exergy has been wasted, that is because expansion ratio is a little bigger. The exergy loss can be effectively reduced by using multi-stage expansion. And to choose the optimizing inlet pressure is also an effective way to reduce the exergy loss.

Table3. The main optimization parameters of process performance.

\begin{tabular}{|l|l|l|}
\hline Name & Exergy loss/kW & Exergy efficiency \\
\hline Expander & 0.79 & $77.31 \%$ \\
\hline
\end{tabular}




\section{Conclusion}

A novel micro power generation process was simulated and analyzed by utilizing natural gas pipeline pressure energy. The voltage was selected as the objective functions and optimized with several key variables of the process. The results showed when the

process properly runs, electricity facilities voltage is $220 \mathrm{~V}$, the best expansion ratio range is 3.0 $\sim 3.0$, the optimal speed range is $650 \sim 750 \mathrm{r} / \mathrm{min}$, the optimal noise range is $71 \sim 72 \mathrm{~dB}$, the corresponding power is $2.6 \sim 2.8 \mathrm{~kW}$. The process capacity is not much, $2 \sim 3 \mathrm{kw}$ output can satisfy the demand of most of the city, to solve the gas pressure regulating stations widespread without electricity, less electricity, and other issues. This process has forward popularization value.

\section{REFERENCES}

1. Zhang Hui et al. 2013. Development and engineering design of technology for utilization of liquefied natural gas (LNG) cold energy in ice-making. Advanced materials research.805-806:519525.

2. Xu Wendong et al. 2010. Recycling of natural gas pressure energy from high-pressure pipeline network. Chemical Industry and Engineering Progress. 29(12): 2385-2389.

3. Mehmet Alparslan Neseli et al. 2015. Energy and exergy analysis of electricity generation from natural gas pressure reducing stations. Energy Conversion and Management 93 (2015): 109-120.

4. Mahmood Farzaneh Gord et al. 2014. Simulation of single acting natural gas Reciprocating Expansion Engine based on ideal gas model. Journal of Natural Gas Science and Engineering. 21 (2014) 669-679.

5. Anonymity. 2009. Electricity generation by using natural gas pressure in Japan. (9):48.

6. Chen Qiuxiong et al.2012. Development and application of technologies for pressure energy electricity generation and ice-making from natural gas pipeline network. Gas \& heat.32(9): A25 27.

7. An Chengming et al. 2012.Development and application of natural gas pressure energy of gas station. Urban Gas.9(451): 25-27.

8. Li Xiaxi et al. 2014. Research and application prospect analysis of power generation potential of Beijing pressure energy of natural gas pipe networks. Urban gas.10(476): 10-15.

9. Zhang Hui. 2014. Integrated technology research on pressure energy of natural gas pipe network.12-17. 